routinely processed histological sections, without such preparation.

Pounder et $a l^{4}$ discuss the various techniques to demonstrate vascular lesions. Bearing in mind that some of these conditions may rely on vascular dynamics and clinicopathological syndromes it is imperative that both clinical and pathological information be combined to arrive at a correct diagnosis.

In conclusion, both surgeons and pathologists should be aware of the possibility of a vascular anomaly of the intestine in patients with fresh rectal bleeding even in the presence of a radiologically demonstrable anatomical abnormality such as diverticular disease, particularly if present in the right hemicolon.

We would like to thank $\mathrm{Mr} \mathrm{C}$ Jeal and $\mathrm{Mr} \mathrm{A}$ Wilson for assistance with photography.

1 Athanasoulis CA, Galdabini JJ, Waltman AC, Novellini RA, Greenfield AJ, Ezpleta ML. Angiodysplasia of the colon a cause of rectal bleeding. Cardiovasc Radiol 1978;1:3-13

2 Boley SS, Samartano R, Adams SA, DiBiase A, Kleinhaus $S$, Sprayregen $S$. On the nature and aetiology of vascula esctasia of the colon. Gastroenterology 1977;72:650-60.

3 Mitsudo SM, Boley SJ, Brandt LJ, Montefusco CM, Sammartano RJ. Vascular ectasia of the right colon in the elderly: a distinct pathological entity. Hum Pathol 1979; 10:585-600.

4 Pounder JD, Rowland R, Pieterse AS, Freeman R, Hunter R. Angiodysplasia of the colon. $\mathcal{F}$ Clin Pathol 1982;35: 824-9.

5 Heyde EC. Gastrointestinal bleeding in aortic stenosis. $N$ Engl f Med 1958;259:196-8.

6 Warkentin TE, Moore JE, Morgan DG. Aortic stenosis and bleeding gastrointestinal angiodysplasia: is acquired von Willebrand's disease the link? Lancet 1992;340:35-37.

7 Allison DJ, Hemingway AP. Angiodysplasia: does old age begin at nineteen? Lancet 1981 ;ii:979-80.

8 Lawson WH. Elastic fibre staining; a modification of the Weigert-Sheridan method. $\mathcal{F}$ Tech Methods 1936;16:42-44

Perry PM, Morson BC. Right sided diverticulosis of the colon. Br ₹ Surg 1971;58:902-4.

10 Morson BC, Dawson IMP, Day DW, Jass JR, Williams GT In: Gastrointestinal Pathology. London: Blackwell Scientific 1990:461-2.

11 Moore JD, Thompson NW, Applman HD, Foley D. Arteriovenous malformations of the gastrointestinal tract. Arch Surg 1976;111:381-9.

12 Griffiths JD. Extramural and intramural blood supply of the colon. BMF 1961;i:323-6.

13 Bird RM, Jaques WE. Vascular lesions of the hereditary haemorrhagic telangiectasia NEngl FMed 1959;260:597-9.

14 Welch $C E$ Christos A, Athanasoulis CA Galdabini J. Haemorrhage from the large bowel with special reference to angiodysplasia and diverticular disease. World $f$ Surg to angiodysplasia

15 Galloway SJ, Casarella WJ, Shimkin PM Vascular malformations of the right colon as a cause of bleeding in formations of the right colon as a cause of bleeding in

16 Love JW, Jahnke EJ, Zacharias D, Davidson WA, Kidde WR, Luan LL. Calcific aortic stenosis and gastrointestinal bleeding. F Engl f Med 1980;302:368-9.

17 Cappell MS, Lebwohl O. Cessation of recurrent bleedin from gastrointestinal angiodysplasia after aortic valve replacement. Ann Intern Med 1986;105:54-7.

\title{
B cell signet-ring cell lymphoma of bone marrow
}

\author{
W G McCluggage, H Bharucha, M El-Agnaf, P G Toner
}

\section{Department of Pathology, Royal Hospitals Trust, Belfast W G McCluggage $\mathrm{H}$ Bharucha P G Toner}

\section{The Queen's} University of Belfast H Bharucha P G Toner

Department of Haematology, The Ulster, North Down Ulster, North Down
and Ards Hospitals Trust M EL-Agnaf

Correspondence to: Dr W G McCluggage, Department of Pathology, Royal Victoria Hospital, Grosvenor Rad Belfast BT12 6BA.

Accepted for publication 8 August 1994

\begin{abstract}
A case of signet-ring cell lymphoma affecting the bone marrow and diagnosed by bone marrow trephine biopsy is reported. Normal marrow was replaced totally by cells with large central vacuoles, many of which displaced the nucleus to the periphery of the cell, imparting a signet-ring appearance. Initially, the favoured morphological diagnosis was metastatic signet-ring adenocarcinoma, but on immunocytochemistry the tumour cells were strongly positive for CD45 (leucocyte common antigen) and the $B$ cell marker CD20 (L26). Electron microscopy revealed electron-lucent vacuoles with no discernable internal structure. The tumour was classified as a high grade centroblastic lymphoma using the upgraded Kiel classification. Despite chemotherapeutic treatment, the patient died during an episode of septicaemic shock within two months of presentation.

(f Clin Pathol 1995;48:275-278)
\end{abstract}

Keywords: Bone marrow trephine biopsy, signet-ring cell lymphoma, electron microscopy.
In a previous issue Talbot et $a l^{1}$ reported the first case of signet-ring cell lymphoma affecting bone marrow. The tumour presented as multiple lytic lesions in the lumbosacral spine and was diagnosed by a computed tomography (CT) guided bone biopsy. Morphologically, the tumour was classified as a high grade centroblastic lymphoma using the upgraded Kiel classification. Immunocytochemistry showed the tumour to be of $\mathbf{B}$ cell lineage. The patient subsequently responded to chemotherapy. Here, we report a further case of signet-ring cell lymphoma affecting bone marrow and diagnosed by bone marrow trephine biopsy. Despite treatment with combination chemotherapy, the patient died during an episode of septicaemic shock within two months of presentation.

\section{Case report}

A 70 year old man was referred by his general practitioner for investigation of central abdominal pain, nausea, vomiting, night sweats, loss of appetite, and weight loss of approximately one stone. 


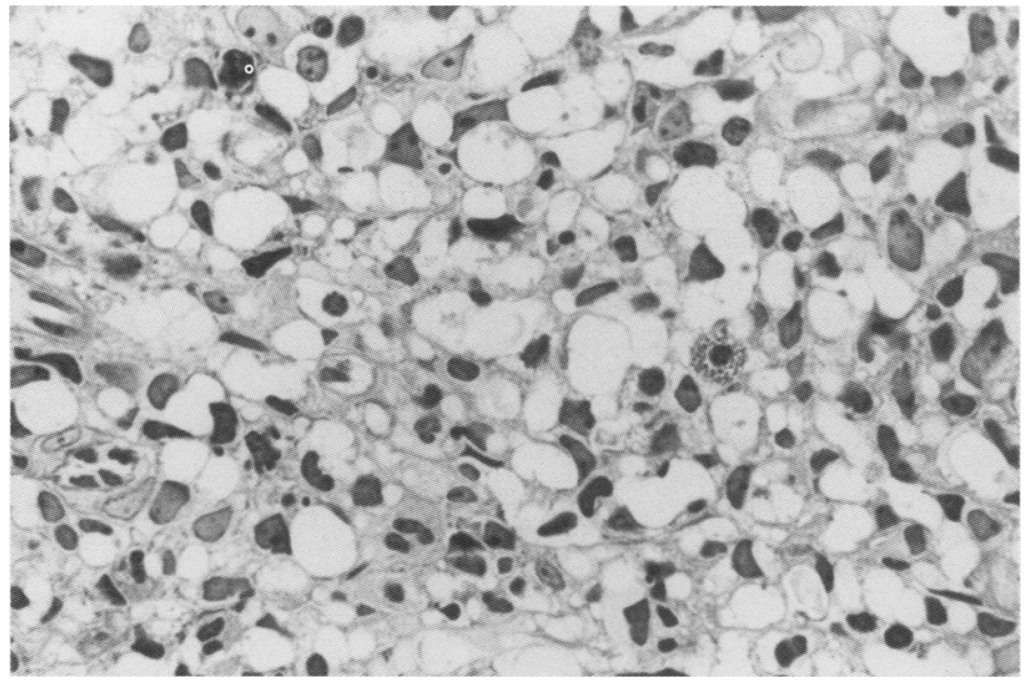

Figure 1 Bone marrow showing diffuse infiltration by lymphoma cells, many of which exhibit a signet-ring morphology. Haematoxylin and eosin.

On initial examination, the patient presented with splenomegaly but no peripheral lymphadenopathy. A full blood count on admission revealed a haemoglobin concentration of $11.5 \mathrm{~g} / \mathrm{dl}$ with normal red indices, a white cell count of $4.4 \times 10^{9} / 1$ and a platelet count of $43 \times 10^{9} / 1$. His erythrocyte sedimentation rate was $57 \mathrm{~mm} /$ first hour. Liver function tests showed a moderate increase in serum alkaline

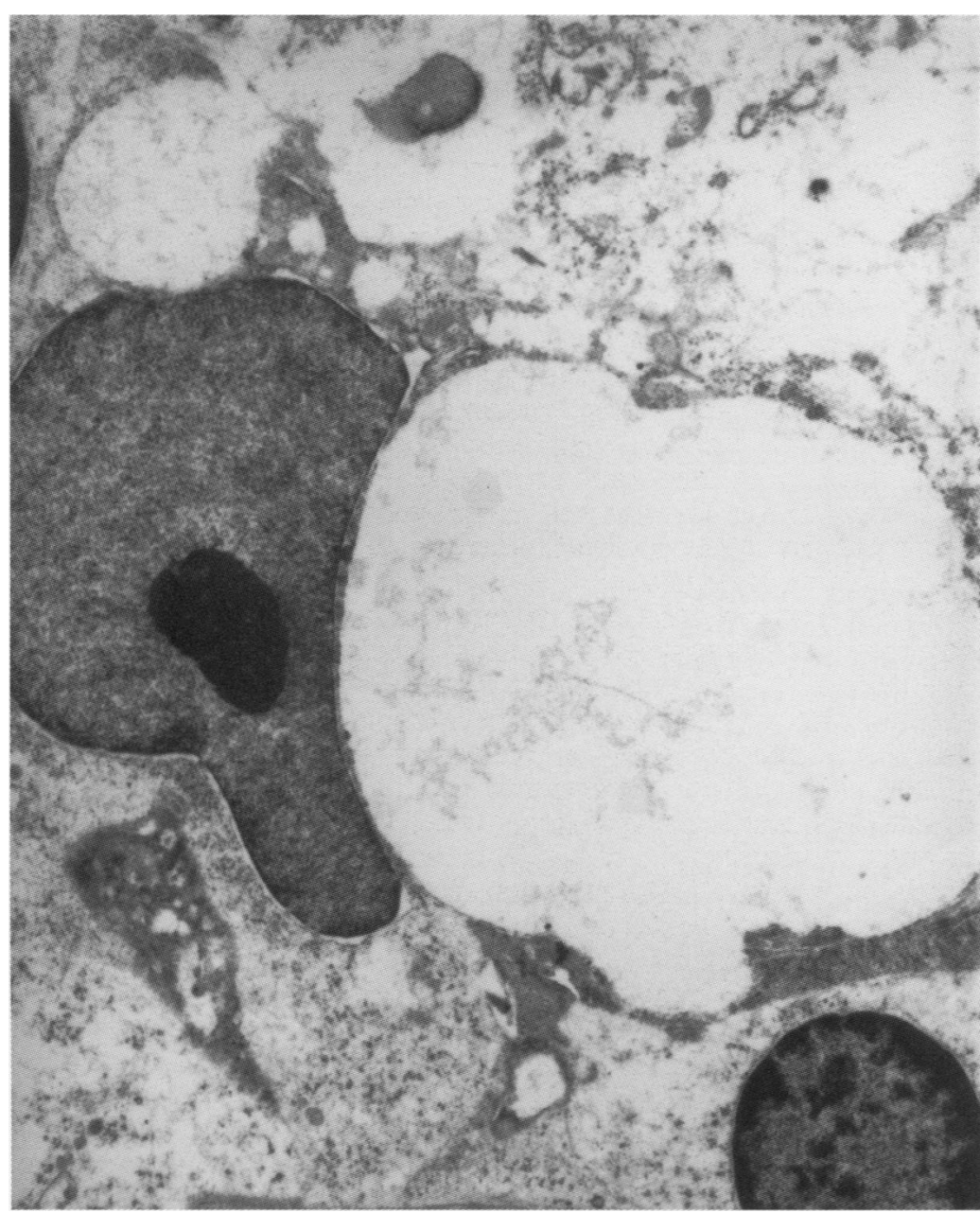

Figure 2 Electron micrograph showing a tumour cell with an intracytoplasmic vacuole compressing the nucleus, imparting a signet-ring appearance (magnification $\times 7000$ ). phosphatase and gammaglutamyl transferase concentrations. Serum electrophoresis and serum calcium were normal and urinary BenceJones proteins were absent. A CT scan confirmed the presence of splenomegaly but there was no evidence of intra-abdominal or mediastinal lymphadenopathy. A peripheral blood film showed a leucoerythroblastic picture. Bone marrow aspiration was performed but this resulted in a dry tap. A bone marrow trephine biopsy specimen was obtained from the iliac crest.

Before the trephine biopsy report, the patient was placed on steroids with symptomatic improvement. Following the diagnosis of lymphoma, the patient was staged as IVB and treatment with cyclophosphamide, doxorubicin, vincristine, and prednisolone (CHOP) was instigated. This was followed by further modest symptomatic improvement and discharge. However, one week later the patient was readmitted with night sweats, weakness and malaise. $\mathrm{He}$ was given a second course of CHOP and again discharged. Repeat CT scan was not performed after the first and second courses of chemotherapy. There was still no evidence of peripheral lymphadenopathy. Red and white blood cell indices and platelet counts, measured on several occasions, were broadly similar to those on admission. He was readmitted two weeks later with a clinical diagnosis of septicaemic shock. Despite intravenous broad spectrum antibiotics, he deteriorated and died on the day of admission. A necropsy was not performed.

\section{Methods}

The bone marrow trephine biopsy was received in $10 \%$ neutral buffered formalin and fixed overnight. Plastic embedding using Polarbed 812 resin was performed and $1 \mu \mathrm{m}$ sections were cut. These were stained with haemotoxylin and eosin, Giemsa, mucicarmine, and periodic acid Schiff (PAS) with and without prior diastase digestion.

Immunohistochemical staining was performed using the avidin-biotin peroxidase technique with antibodies against CD45 (leucocyte common antigen (LCA)), CD20 (L26), CD45Ro (UCHLI), CD3, IgG, IgM, $\kappa$ and $\lambda$ light chains, Cam $5 \cdot 2$, epithelial membrane antigen (EMA), and S-100.

The plastic embedded tissue was processed for transmission electron microscopy. Ultrathin sections from several representative areas were stained with uranyl acetate and lead citrate.

\section{Pathological findings}

The bone marrow was diffusely infiltrated by sheets of cells, the cytoplasm of which was occupied by large vacuoles, many of which compressed and displaced the nucleus to the periphery of the cell resulting in a signet-ring appearance (fig 1). Areas of necrosis were not identified. On high power examination, it could be discerned that in the few cells without nuclear compression and distortion, most of the nuclei were vesicular with one to three nucleoli. 
Smaller numbers of small cleaved cells and small lymphocytes were also identified. A nodular pattern was not observed, the cellular infiltrate being diffuse with no predilection for paratrabecular aggregation. The initial preferred morphological diagnosis had been metastatic signet-ring adenocarcinoma. However, this was revised following the results of histochemical and immunohistochemical analysis. Using the upgraded Kiel classification, the tumour was finally classified as a high grade centroblastic lymphoma.

The results of special stains were as follows. No intracytoplasmic mucins were identified with the mucicarmine or PAS diastase stains. Tumour cells were negative for Cam 5.2, EMA and S-100. All cell types identified (centroblasts, centrocytes, lymphocytes) showed strong positive staining with LCA and the B cell marker L26 and were negative with the T cell markers UCHLI and CD3. No intracytoplasmic or surface staining could be identified with IgG or IgM, and $\kappa$ and $\lambda$ light chains showed no significant staining.

Ultrastructural examination showed the preservation of cellular detail to be less than perfect. However, the principal cell type showed nuclei with sparse chromatin and one or more prominent nucleoli. Lesser numbers of cells with nuclear identations or grooves were also observed. Most of the cells contained large intracytoplasmic vacuoles, some of which indented and compressed the nucleus imparting a signet-ring appearance (fig 2 ). These vacuoles were electron-lucent with no discernable structure. Occasional vacuoles were bound to the membrane. In addition to these vacuoles the cell cytoplasm contained a moderate amount of rough endoplasmic reticulum and sparse numbers of other organelles. There was no evidence of epithelial differentiation such as intercellular adhesion specialisations or microvillous processes. There was no evidence of melanocytic differentiation; melanosomes and premelanosomes were not identified.

\section{Discussion}

The first cases of signet-ring cell lymphoma were reported by $\mathrm{Kim} e t a^{2}$ in 1978 when they described seven non-Hodgkin's lymphomas arising within lymph nodes. These lymphomas were characterised by a follicular growth pattern and an abundance of cells containing clear vacuolated cytoplasm resulting in a signet-ring morphology. The authors attributed this signetring appearance to the accumulation of intracytoplasmic immunoglobulin and offered both immunohistochemical and ultrastructural support for this. Immunohistochemically, they were able to demonstrate intracytoplasmic IgG in three cases, all of which contained cells with clear, vacuolated cytoplasm. Intracytoplasmic IgM was demonstrated in a further three cases, whose tumours were composed of cells with abundant eosinophilic cytoplasm, imparting a Russell body-like appearance.

Since the original description by Kim et $a l^{2}{ }^{2}$ approximately 40 cases of signet-ring cell lymphoma have been reported in the literature, the majority involving lymph nodes. Bone marrow involvement appears to be rare, not having been documented prior to the description by Talbot et al. ${ }^{1}$ The majority of cases of signetring cell lymphoma have been of $B$ cell lineage ${ }^{1-4}$ and derived from follicular centre cells. Most authors have been able to demonstrate intracytoplasmic accumulation of immunoglobulin and have concluded that the signetring appearance is caused by the abnormal production or secretion, or both, of immunoglobulin products. However, several reports of $\mathrm{T}$ signet-ring cell lymphoma have appeared in the literature, ${ }^{5-7}$ mostly exhibiting cutaneous involvement. ${ }^{56}$ These cases demonstrate that the presence of signet-ring cells within a lymphoma should not be considered proof of B cell origin.

Electron microscopy of several $\mathrm{T}$ signet-ring cell lymphomas has revealed giant cytoplasmic vacuoles identical with those reported in B cell types. Clearly, in these $T$ cell lymphomas the signet-ring morphology cannot be explained on the basis of intracytoplasmic immunoglobulin accumulation. It has been postulated that the vacuolated appearance may be a result of abnormal internalisation of surface $T$ antigens or the sequestration of $T$ antigen containing, Golgi derived, vesicles. ${ }^{7}$ Such aberrant membrane recycling may be the common denominator of signet-ring formation in both $\mathrm{B}$ and $\mathrm{T}$ signetring cell lymphomas. The absence of demonstrable intracytoplasmic immunoglobulin by immunohistochemical techniques in the present case, as well as in several previously reported B signet-ring cell lymphomas ${ }^{1}$ could be explained on this basis. A possible alternative explanation for the failure to demonstrate intracytoplasmic immunoglobulin accumulation in the present case is our routine use of a plastic embedding technique to preserve cellular morphology in bone marrow trephine biopsy specimens. With such plastic embedding techniques, antigen preservation may be impaired and negative immunostaining can be difficult to interpret. Strong positive immunostaining of tumour cells, however, was obtained in the present case with CD45 and CD20 antibodies.

The presence of signet-ring cells within a lymphoma does not seem to influence the clinical outcome, the classification and behaviour of these lymphomas being dependent on nuclear morphology. As in the present case, the nuclear features may be best appreciated in those cells which do not have the signet-ring appearance and therefore do not sustain nuclear compression and distortion.

As in the present case, signet-ring cell lymphomas may present in a variety of extranodal sites without evidence of lymphadenopathy, these lesions having been described in a variety of organs including skin, ${ }^{5-7}$ stomach, ${ }^{8}$ thyroid gland, ${ }^{9}$ and salivary gland. ${ }^{10}$ The presence of large numbers of cells with a signet-ring appearance may suggest a diagnosis other than lymphoma. Signet-ring cells are seen in a variety of tumours including adenocarcinoma, malignant melanoma and liposarcoma. Unless pathologists are aware of the existence of this morphological variant of lymphoma, an er- 
roneous diagnosis may be reached, resulting in inappropriate investigation and treatment. The diagnostic difficulties may be further compounded in small bone marrow trephine biopsy specimens where the usual follicular growth pattern of these lymphomas may not be appreciated. In the present case the initial favoured morphological diagnosis was metastatic signet-ring adenocarcinoma and a diagnosis of lymphoma was only reached after the histochemical and immunohistochemical results became available. Electron microscopy may also help by showing lymphoid features and an absence of epithelial or melanocytic differentiation.

1 Talbot DC, Davies JH, MacLennan KA, Smith IE. Signetring cell lymphoma of bone marrow. $\mathcal{f}$ Clin Pathol 1994; 47:184-6.

2 Kim H, Dorfman RF, Rappaport H. Signet-ring cell lymph- oma: a rare morphological and functional expression of nodular (follicular) lymphoma. Am $\mathcal{F}$ Surg Pathol 1978;2: 119-32.

3 Silberman S, Fresco R, Steinecker PH. Signet-ring cell lymphoma: a report of a case and review of the literature. lymphoma: a report of a case and

4 Harris M, Eyden B, Read G. Signet-ring cell lymphoma: a rare variant of follicular lymphoma. $\mathcal{F}$ Clin Pathol 1981; 34:884-91.

5 Cross PA, Eyden BP, Harris M. Signet-ring cell lymphoma of T-cell type. $\mathcal{F}$ Clin Pathol 1989;42:239-45.

6 Weiss LM, Wood GS, Dorfman RF. T-cell signet-ring cell lymphoma: a histologic, ultrastructural and immunohistochemical study of two cases. Am $\mathcal{F}$ Surg Pathol 1985 9:273-80.

7 Grogan TM, Payne CM, Richter LC, Rangel CS. Signetring cell lymphoma of T-cell origin: an immunocytochemical and ultrastructural study relating giant vacytochemical and ultrastructural study relating giant vamembrane. Am f Surg Pathol 1985;9:684-92.

8 Tungekar MF. Gastric signet-ring cell lymphoma with alpha heavy chains. Histophathology 1986;10:725-33.

9 Allevato PA, Kini SR, Rebuck JW, Miller JM, Hamburger $\mathrm{J}$. Signet-ring cell lymphoma of the thyroid: a case report. Hum Pathol 1985;16:1066-8.

10 Stramignoni A, Palestro G, Coda R, Micca FB, Stramignoni D. Signet-ring cell lymphoma in salivary gland: an immunohistochemical and ultrastructural study. Appl Pathol 1984;2:76-84.

\title{
Degenerative changes in myometrium simulating diffuse leiomyomatosis after treatment with gonadotrophin releasing hormone analogue
}

\author{
M Jeffers, C Cowan, C B Lunan
}

\begin{abstract}
Degenerative changes are encountered relatively frequently in uterine leiomyomas. Morphologic changes within leiomyomas, particularly necrosis and alterations in cellularity, have been described following treatment with gonadotrophin releasing hormone analogue, but the effects of this form of treatment on the morphology of the normal myometrium are less well documented. A case is reported of a 42 year old woman with a history of menorrhagia in whom a combination of degenerative and iatrogenic changes resulted in a histological appearance resembling diffuse leiomyomatosis.

(f Clin Pathol 1995;48:278-280)
\end{abstract}

Keywords: Leiomyomatosis, gonadotrophin releasing hormone analogue.

Gonadotrophin releasing hormone ( $\mathrm{GnRH}$ ) analogues are used in the management of patients with uterine leiomyomas. Reduction in leiomyoma volume occurs following
GnRH analogue administration, possibly because of atrophy of smooth muscle cells. ${ }^{1}$ Changes in cellularity, necrosis, and haemorrhage have been described in leiomyomas following treatment with $\mathrm{GnRH}$ analogues, ${ }^{1-4}$ but the range of histopathological changes resulting from the administration of GNRH analogues has yet to be fully defined. Here, we report a case in which features suggestive of diffuse leiomyomatosis were present in a hysterectomy specimen following administration of goserelin, a GnRH analogue.

\section{Case report}

A 42 year old woman had been attending the gynaecology clinic for four years with a history of menorrhagia. Examination at initial presentation revealed a small mobile uterus. She was started on a cyclical progestogen but defaulted from follow-up. Two years later, the patient presented with acute urinary retention and was found to have an enlarged uterus with fibroids. She also complained of menorrhagia; endometrial curretage was performed yielding normal secretory endometrium. She was started on a progesterone 